\title{
Gestão das atividades de produção do Sururu em Alagoas: relato da utilização de ferramentas e técnicas de gestão de projetos
}

Carlos Eugênio Silva da Costa ceadm2011@gmail.com Universidade Federal de Alagoas

Victor Hugo Lessa Pierre

victorplhp@gmail.com

Daniel Cabral de Almeida danielcabral @hotmail.com

Universidade Federal de Alagoas

Antônio Carlos Silva Costa acscosta@gmail.com

Universidade Federal de Alagoas

Waldemar Antônio da Rocha de Souza

Waldemar.souza@feac.ufal.br

Universidade Federal de Alagoas

\section{RESUMO}

Este artigo validou a aplicação de ferramentas e técnicas de gerenciamento de projetos em projetos públicos por meio de um caso prático direcionado à gestão das atividades de produção do sururu de forma sustentável ambiental e socialmente no Estado de Alagoas. Examinaram-se as particularidades dos projetos públicos, como elas interferem no processo de gerenciamento e quais as ferramentas e técnicas mais adequadas a serem aplicadas nesse processo. Por fim, avaliou-se o projeto formulado para aprimorar a produção de sururu, constituído com a aplicação de ferramentas e técnicas do Project Management Body of Knowledge (PMBOK) e de sua extensão voltada ao setor público, o Government Extensionto A Guide to the Project Management Body of Knowledge. A análise de resultados demonstrou os principais aspectos do processo de gerenciamento de um projeto público voltado a um setor produtivo, alinhado com ações de responsabilidade ambiental e social e baseado nas instruções do guia PMBOK, assim como registrou as particularidades do setor público a serem observadas em cada etapa. Concluiu-se que as ferramentas e técnicas do PMBOK satisfizeram às demandas presentes no processo de gerenciamento do projeto público estudado, facilitaram sua gestão e adaptaram-se àssuas peculiaridades.

PALAVRAS-CHAVE: administração de projetos; projetos de desenvolvimento econômico; projetos de desenvolvimento social;guia do conjunto de conhecimentos em gerenciamento de projetos (Guia PMBOK). 


\section{INTRODUÇÃO}

Os projetos públicos possuem particularidades que os diferenciam dos projetos da iniciativa privada. O governo atua em prol da sociedade e dos contribuintes. Seu objetivo é atender às demandas sociais, fundamentadas em lei, e não à livre vontade de seus gestores. O uso de seus recursos, bem como a aquisição de bens e serviços, devem obedecer à leis específicas que regulam a utilização da coisa pública. Por essa razão, é necessário ferramentas e técnicas compatíveis com tais peculiaridades.

Diante disso, criou-se o PMBOK (PMI, 2013), um guia com técnicas e ferramentas para gestão de projetos, que recebeu posteriormente uma extensão com alternativas direcionadas ao setor público complementares aquelas indicadas pelo PMBOK original. Com base nessas ferramentas e técnicas, esquematizou-se o projeto "Gestão das Atividades de Produção do Sururu em Alagoas". Seu foco foi propor um modelo organizacional ótimo para aprimorar o processo de produção de sururu desenvolvido no Complexo Estuarino Lagunar Mundaú-Manguaba (CELMN), localizado no Estado de Alagoas, com emprego de ações direcionadas à sustentabilidade social e ambiental.

Não obstante abundante literatura sobre gestão de projetos, existem poucos trabalhos que abordam a aplicação de suas técnicas e ferramentas no gerenciamento de projetos públicos, o que pode ser identificado por meio de busca em bases de dados, como Scielo (2017), Spell (2017) e o Google acadêmico (GOOGLE, 2017) . Acreditou-se, entretanto, que os projetos públicos, também poderiam ser beneficiados com a utilização das ferramentas e técnicas da gestão de projetos, desde que aplicadas as adaptações necessárias às particularidades que o setor público exige.

Essa escassez de informações e as incertezas relacionadas à gestão de projetos públicos inspiraram a articulação deste estudo, o qual foi desenvolvido na disciplina Gestão de Projetos do Mestrado Profissional em Administração Pública da Universidade Federal de Alagoas. Nele, constituiu-se o projeto de gestão da produção do sururu com aproveitamento de resíduos da produção e amparo à mulher produtora, então previsto na pasta de projetos da Secretaria da Mulher e dos Direitos Humanos de Alagoas - SEMUDH-AL. Para isso, aplicaram-se as ferramentas e técnicas do Project Management BodyofKnowledge (PMBOK) e de sua extensão voltada ao setor público, o GovernmentExtensionto a Guidetothe Project Management BodyofKnowledge, com ênfase nas nove áreas de conhecimento em gestão de projetos estabelecidas no PMBOK (PMI, 2013)

O objetivo principal deste trabalho foi validar a aplicação das ferramentas e técnicas de gerenciamento de projetos na elaboração do projeto público de gestão das atividades de produção do sururu em Alagoas. Como objetivos específicos, examinaram-se ferramentas e técnicas de gerenciamento de projetos, com especial atenção àquelas apresentadas pelo PMBOK; em seguida, ilustrou-se seu emprego na gestão do projeto público de gestão das atividades de produção do sururu em Alagoas; e, por fim, examinaram-se os principais pontos do projeto formulado.

Organizou-se o presente artigo em 5 seções, incluindo esta, que é a seção 1. Na seção 2, expressou-se o Referencial Teórico, o qual discutiu os projetos públicos, seu gerenciamento e suas particularidades. A seção 3 descreveu a 
Metodologia de Pesquisa aplicada ao estudo, a hipótese investigada e a forma como constituiu-se o projeto. Na seção 4, Análise de Resultados, discutiu-se o relato da experiência de gerenciamento do projeto público de gestão da produção do sururu em Alagoas, bem como as ferramentas e técnicas aplicadas. Por fim, a seção 5 expressa as Considerações Finais do artigo e aponta trabalhos futuros para aprimorar o tema estudado.

\section{PROJETOS PÚBLICOS}

\section{CONCEITO DE PROJETO E PARTICULARIDADES DOS PROJETOS PÚBLICOS}

Tuman (1983) conceituou projeto como um conjunto organizado de pessoas direcionado a um propósito e objetivo específico.Verzuh (2000), por sua vez, definiu projetos como um conjunto de atividades com começo e fim bem definidos, que geram um produto singular, e que, para chegar do início até seu fim, percorre uma sequência de atividades agrupadas em fases.

Shenhar e Dvir (2010) esclarecem que as atividades executadas pelas organizações se dividem em operações e projetos. As operações empregam práticas que não são temporárias, mas rotineiras e repetitivas, destinadas a confeccionar produtos idênticos, como é o caso das operações de manufatura.

Os projetos, por sua vez, registram ações peculiares, inéditas, voltadas a aprimorar e inovar as atividades da entidade. Possuem duração limitada, são planejados, executados e controlados, em uma abordagem sistêmica, assim como relacionam recursos e atividades destinados a um resultado de maneira processual (SILVA, 2013). Importante destacar neste contexto, a definição trazida pelo PMBOK, o qual define projeto como um esforço voltado à criação de um produto em um determinado período de tempo.

No tocante aos projetos públicos, é preciso esclarecer que a forma como operam as organizações públicas difere significativamente das organizações privadas, principalmente por causa das legislações específicas e do público alvo a ser atingido ou beneficiado (PMI, 2001). Segundo Grego (2009), os projetos públicos não possuem como motivação principal o retorno financeiro, mas sim o retorno social em um período mais longo de maturação. Essa noção é importante para entender que desafios seus gerentes devem superar.

Além disso, necessita de detalhamentos isolados para que se enquadre numa realidade vinculada à legislação e demais regimentos decorrentes da burocratização da administração pública. Dessa forma, as organizações públicas têm o intuito de concretizar seu fim essencial, que é o bem-estar da coletividade. (SOUZA; REINHARD, 2016)

Outra grande diferença entre as ações governamentais e privadas é no tocante a seusstakeholders.Stakeholders são as partes interessadas, ou seja, os indivíduos e organizações direta ou indiretamente envolvidos no projeto ou cujos interesses podem ser afetados. A atividade da Administração Pública tem a coletividade como financiadora e beneficiária de suas ações, a qual possui direitos legalmente determinados a serem concretizados. Já o setor privado tem compromisso com as demandas de seus clientes e norteiam suas ações com objetivo no lucro. É necessário, pois, identificar os stakeholderse gerenciar 
adequadamente suas necessidades e expectativas a fim de garantir o sucesso do projeto (SILVA, 2013; WIRICK, 2011).

Mais uma distinção que pode ser apontada é que o governo atua em caráter de monopólio, diferentemente do ambiente de competição nato às empresas privadas (OSBORNE; GAEBLER, 1997). Carneiro (2006) cita quatro aspectos importantes, destacando as limitações e especificidades relativas ao gerenciamento de projetos no setor público:

- complexidade: projetos governamentais têm grande interconexão com outros projetos e ações;

- duração: alguns projetos governamentais são muito demorados;

- governança: muitos projetos governamentais possuem vários stakeholdersindependentes;

- benefícios: poucas vezes são benefícios monetários que se esperam e sim outros benefícios qualitativos, de difícil mensuração.

\section{O GERENCIAMENTO DE PROJETOS PÚBLICOS}

O gerenciamento dos processos é essencial para a consecução dos objetivos das organizações. Essa atividade compreende um conjunto organizado de ações voltadas a disponibilização de bens e serviços para seus clientes, que, no caso do setor público, é o próprio contribuinte (Rozenfeld et al., 2006; WIRICK, 2011).

Com o aumento populacional, evolução da sociedade e ampliação dos direitos, as organizações têm que lidar com mudanças constantes das demandas sociais. Esse fato acarretou na crescente demanda por projetos. Assim, a partir dos anos 1990, esquematizaram-se as atividades de gerenciamento de projetos em guias e manuais, dos quais o mais festejado foi o Guia PMBOK (Carvalho e Rabechini Jr., 2011).

MUNNS e BJEIRMI (1996) distinguiram os conceitos de projeto e gerenciamento de projetos. Segundo os autores, projeto é o alcance de um objetivo específico por meio de uma série de tarefas e atividades que utilizam recursos, com previsão para início e fim. Gerenciamento do projeto é o processo utilizado para atingir os objetivos do projeto.

O PMBOK (PMI, 2013) apresentou conceito semelhante de gestão de projetos. Definiu-se gerenciamento de projetos como a aplicação de conhecimentos, habilidades, ferramentas, e técnicas em atividades do projeto, para satisfazer as necessidades do projeto. Identificaram-se cinco fases, dependentes entres si, a serem percorridas ao longo do gerenciamento do projeto: iniciação, planejamento, execução, controle e encerramento. Aplica-se essa sequência de fases em qualquer projeto, não importando sua área de interesse ou setor.

A iniciação é composta pelas percepções, vontades e interesses que levaram à elaboração do projeto. No projeto de gestão do sururu, expressou-se quando da percepção do modo de produção inadequado, da grande quantidade de resíduos depositados como lixo e das más condições de trabalho dos produtores. Esse cenário provocaram o desejo de superação desse cenário por parte das organizações públicas e dos pesquisadores envolvidos na formulação do projeto.

A fase de planejamento abrange a elaboração do escopo do projeto, do 
cronograma, da avaliação de riscos, da constituição de um orçamento para o projeto, definição de indicadores de desempenho e planejamento das aquisições e a preparação do plano do projeto (PMI, 2013; CAMARGO, 2014)

A fase de controle reúne o monitoramento e mensuração regulares do desempenho do projeto, de forma a identificar variações em relação ao planejado. Garante que o projeto permanecerá dentro dos padrões idealizados inicialmente, controlando seu desenvolvimento e eventuais alterações ou adaptações que se fizerem necessárias. Por fim, a fase de encerramento ilustra o fechamento formal do projeto e registro dos sucessos e falhas para aperfeiçoamento de projetos futuros (SNYDER, 2013).

Durante as várias fases de um projeto, diversas ferramentas e técnicas devem ser utilizadas. Algumas dessas ferramentas e técnicas são utilizadas para fins específicos, como o controle de custos e qualidade. Aplicou-se, neste artigo,as fases de iniciação e planejamento, haja vista que o projeto foi apresentado durante um workshop na Secretaria de Estado do Planejamento, Gestão e Patrimônio de Alagoas - SEPLAG a alguns gestores públicos, dentre eles alguns secretários de estado, que o aprovaram, para uma posterior execução. O próximo tópico apresentará as áreas de conhecimento retratadas na elaboração do projeto.

\section{ÁREAS DE CONHECIMENTO DA GESTÃO DE PROJETOS}

Além das fases do processo de gestão de projetos explicadas anteriormente, o PMBOK (PMI, 2013) relata que o gerenciamento demanda a administração de nove áreas de conhecimento, que ilustram os principais aspectos a serem traçados durante sua execução. Elas versam sobre a concatenação dos elementos mais importantes de um projeto, quais sejam: integração, escopo, prazos, custos, recursos humanos, aquisições, qualidade, riscos e comunicação (Rabechini, CARVALHO \& Laurindo, 2002). As nove áreas, com suas respectivas descrições, foram expressas nafigura 1. 
Figura 1- Ilustração das áreas de conhecimento com suas respectivas descrições.

\begin{tabular}{|c|c|}
\hline Área de Conhecimento & Descrição \\
\hline Integração & $\begin{array}{l}\text { A integração consiste na coordenação do projeto para } \\
\text { que as áreas de conhecimento formem um todo coeso } \\
\text { (CAMARGO, 2014) }\end{array}$ \\
\hline Escopo & $\begin{array}{l}\text { O escopo do projeto constitui-se em uma descrição } \\
\text { documentada de um projeto, quanto a seus resultados, } \\
\text { abordagem e conteúdo. É um resumo de suas } \\
\text { consequências esperadas, permite uma compreensão } \\
\text { do que se pretende fazer e com que finalidade } \\
\text { (VALERIANO, 2004). }\end{array}$ \\
\hline Tempo & $\begin{array}{l}\text { O gerenciamento do tempo é um aspecto importante } \\
\text { do gerenciamento de projetos, pois envolve a } \\
\text { manutenção das atividades do projeto no que se refere } \\
\text { à estimativa da duração das atividades num cronograma } \\
\text { (HELDMAN, 2006) }\end{array}$ \\
\hline Custos & $\begin{array}{l}\text { Gerenciamento de custos é uma área do conhecimento } \\
\text { que gira em torno de custos e orçamentos sob os } \\
\text { processos estimativa de custos, elaboração de } \\
\text { orçamentos de custos e controle de custos (HELDMAN, } \\
2006 \text { ) }\end{array}$ \\
\hline Riscos & $\begin{array}{l}\text { Gerenciamento de riscos é "um processo sistemático de } \\
\text { definição e resposta aos riscos do projeto", com o } \\
\text { objetivo de maximizar eventos positivos e minimizar as } \\
\text { consequências destes (DINSMORE; CAVALIERI, 2008) }\end{array}$ \\
\hline Comunicação & $\begin{array}{l}\text { O planejamento das comunicações define as estratégias } \\
\text { e processos para a comunicação das informações do } \\
\text { projeto a todas as partes interessadas. (CAMARGO, } \\
\text { 2014) }\end{array}$ \\
\hline Recursos humanos & $\begin{array}{l}\text { Em gerenciamento de projetos, os Recursos Humanos } \\
\text { consistem basicamente na gestão das pessoas que irão } \\
\text { trabalhar no projeto. (CAMARGO, 2014) }\end{array}$ \\
\hline Qualidade & $\begin{array}{l}\text { O gerenciamento da qualidade do projeto inclui os } \\
\text { processos e as atividades da organização executora que } \\
\text { determinam as políticas de qualidade, os objetivos e as } \\
\text { responsabilidades, de modo que o projeto satisfaça às } \\
\text { necessidades para as quais foi empreendido (Guia } \\
\text { PMBOK, 2013) }\end{array}$ \\
\hline Aquisições & $\begin{array}{l}\text { O gerenciamento das aquisições do projeto inclui os } \\
\text { processos necessários para comprar ou adquirir } \\
\text { produtos, serviços ou resultados externos à equipe do } \\
\text { projeto. A organização pode ser tanto o comprador }\end{array}$ \\
\hline
\end{tabular}


Fonte: Elaborada pelos autores.

O sucesso no gerenciamento de projetos é viabilizado pela excelência nessas áreas. Elas são comumente aplicadas em projetos orientados ao setor privado, porém são abrangentes e úteis para garantir o sucesso de projetos de mesma natureza. Acredita-se, pois, que projetos públicos também podem se beneficiar da utilização das ferramentas e técnicas aplicadas em cada área de conhecimento.

\section{METODOLOGIA}

O trabalho fundamentou-se na abordagem de estudo de caso, a fim de investigar a hipótese de que é cabível a aplicação de ferramentas e técnicas de gerenciamento de projetos nos projetos desenvolvidos pelo setor público, desde que adaptados às suas particularidades. Para isso, formulou-se um estudo prático com parceria entre o curso de Mestrado Profissional em Administração Pública da Universidade Federal de Alagoas e o Governo do Estado de Alagoas, por meio da qual articulou-se o projeto público de Gestão das Atividades de Produção do Sururu em Alagoas vinculado à Secretaria de Estado da Mulher e dos Direitos Humanos - SEMUDH.

Examinaram-se então as principais ferramentas e técnicas aplicáveis a projetos, identificaram-se aquelas voltadas ao setor público, e, dessa pesquisa, foram selecionadas as mais adequadas, cuja aplicação prática ilustrou-se no projeto traçado. As bases teóricas para o processo de gerenciamento do projeto foram os livros PMBOK (PMI, 2013) e sua extensão voltada ao setor público; o livro Public-sector project management: meeting thechallengesandachievingresults, deDavid Wirick (WIRICK, 2011); a obra Gerenciamento de projetos: fundamentos e prática integrada, de Marta Rocha Camargo (CAMARGO, 2014); e o livro A Project Manager's Book offorms: A Companion tothe PMBOK Guide, de Cynthia StackpoleSnyder(SNYDER, 2013).

Empregou-se pesquisa qualitativa, aplicada e exploratória, cuja finalidade foi produzir conhecimentos para utilização prática no gerenciamento de outros projetos públicos, de forma a auxiliar na interpretação de fenômenos e solução de entraves específicos, com base nas hipóteses aqui descritas (GIL, 2010).

A pesquisa expressou caráter descritivo, cuja coleta de dados se deu por meio de análise documental e levantamento bibliográfico. Ela classifica-se como descritiva porque descreveram-se as características dos projetos públicos e de seu processo de gerenciamento por meio do estudo de caso prático. (GIL, 2010).

O levantamento bibliográfico analisou o tema por meio de bases teóricas já publicadas na literatura. Seu objetivo foi esclarecer tudo o que foi escrito sobre determinado assunto. Já a pesquisa documental empregou a análise dos documentos até então privados de tratamento analítico, passíveis de elaboração (Marconi e Lakatos, 2010)

A pesquisa documental iniciou-se com a investigação dos temas "Projetos Públicos" e "Gerenciamento de Projetos Públicos" nos sistemas de busca do 
Google Acadêmico (GOOGLE, 2016), no sistema de pesquisa Spell (SPELL, 2016) e na biblioteca científica eletrônica Scielo (SCIELO, 2016).

Os termos usados nos mecanismos de busca foram: projetos públicos, gerenciamento de projetos públicos, projetos governamentais e gerenciamento de projetos. Pesquisaram-se as mesmas expressões no idioma inglês. O procedimento de busca foi repetido em periódicos nacionais voltados ao campo da Administração Pública, tais como RAE-Eletrônica, RAC, RAP e Rausp.

Concluída a pesquisa documental, foram coletadas informações por meio de entrevistas, que constam nos relatórios de visitas técnicas, realizadas com especialistas e algumas das partes direta ou indiretamente envolvidas no processo produtivo do sururu, dentre eles: pescadores, presidente da colônia de pescadores Z5,presidente da Federação dos Pescadores do Estado de Alagoas FEPEAL, servidores da SEMUDH, um consultor do Serviço Nacional de Aprendizagem do Cooperativismo no Estado de Alagoas - SESCOOP/AL, servidores da Superintendência de Limpeza Urbana de Maceió - SLUM, servidores da Secretaria de Estado da Agricultura, Pecuária, Pesca e Aquicultura de Alagoas SEAGRI, além de diversas autoridades públicas interessadas na atividade, comerciantes, empresários da rede hoteleira e pesquisadores especialistas no tema.

\section{ANÁLISE DE RESULTADOS}

$\mathrm{Na}$ análise de resultados, descreveu-se o processo de elaboração do projeto público de de Gestão das Atividades de Produção do Sururu em Alagoas, relataram-se as dificuldades encontradas pela equipe de formulação e gerenciamento do projeto, ilustraram-se as técnicas e ferramentas aplicadas, descreveram-se as etapas percorridas e avaliou-se o resultado final do projeto face a seus objetivos.

\section{O PROJETO PÚBLICO DE GESTÃO DAS ATIVIDADES DE PRODUÇÃO DO SURURU EM ALAGOAS}

Desenvolvido pelos autores deste artigo, alunos e professores do Mestrado Profissional em Administração Pública em rede nacional - PROFIAP, o projeto "Gestão das atividades de produção do sururu em Alagoas" surgiu no contexto da falta de organização e higiene e da situação de vulnerabilidade dos produtores e produtoras de sururu, localizados principalmente na cidade de Maceió-AL.

O projeto, por vislumbrar as mulheres em situação de vulnerabilidade como seu principal público-alvo, foi desenvolvido em parceria com a Secretaria de Estado da Mulher e dos Direitos Humanos em Alagoas - SEMUDH.

A operacionalização do projeto desenvolvido demandou o envolvimento de diversas outras secretarias de estado, como a secretaria de planejamento e a secretaria de agricultura e pesca, entidades locais, pesquisadores, além da realização de diversas visitas técnicas e reuniões, sendo que a utilização das ferramentas de gestão de projetos mostrou-se importante para o sucesso da iniciativa. O próximo tópico apresenta maiores detalhes deste projeto, por meio da demonstração de como o seu desenvolvimento foi conduzido. 


\section{O PROJETO - VISÃO GERAL}

A produção de sururu no estado de Alagoas envolvia a extração proveniente do Complexo Estuarino Lagunar Mundaú-Manguaba (CELMN). Sua importância econômica e cultural para a população era tamanha, que o Concelho Estadual de Cultura de Alagoas (CEC) transformou o sururu em patrimônio imaterial do estado de Alagoas em 2014. A principal colônia produtora, denominada "Colônia de Pescadores Z05 Anibal Gama", localizava-se na região periférica da Zona Sul da cidade e constituía-se em uma das principais fontes de renda da população que habita a região.

Esquematizou-se o projeto com os objetivos de implementar uma produção sustentável econômica, social e ambientalmente. Os produtos e resultados planejados para o projeto foram: a produção do sururu com qualidade comprovada, a criação de cooperativa de produtores de sururu, a melhoria do nível socioeconômico das mulheres produtoras, a diminuição da desigualdade social e da violência, a melhoria na limpeza urbana, melhoria da saúde da população envolvida, elevação da situação econômica dos produtores do sururu e preservação do meio-ambiente.

Identificou-se um cenário produtivo que envolvia diretamente cerca de 500 pessoas. O volume médio extraído era de aproximadamente 21 toneladas de molusco por dia, das quais aproximadamente 2,5 toneladas eram de filé. Ou seja, a cada 21 toneladas extraídas, uma média de 2,5 eram aproveitadas e o restante, compostas pela casca, descartadas. Segundo os produtores entrevistados, o molusco variava de tamanho principalmente de acordo com a estação do ano. Dessa forma para cada 1 quilo de filé, estimaram-se necessários entre 8 e 20 quilos de sururu com casca, a depender de seu tamanho (Coutinho et al., 2014).

O preço de venda do quilo do filé costumava ser de $\mathrm{R} \$ 8,00$, podendo variar entre $R \$ 5,00$ e $R \$ 15,00$, dependendo da produção, da época do ano e do canal por meio dos qual o produto chegava ao consumidor.

Constatou-se que as condições de produção não atendiam critérios de segurança alimentar. Inexistem luvas, toucas, aventais ou mesas de material adequado. Não havia sistema de lavagem com água potável. O pescado era transportado e cozido em latas de tinta velhas, com a própria água da lagoa. $\mathrm{O}$ tratamento era feito em estruturas inadequadas, muitas vezes a céu aberto. Não registrou-se aplicação de normas ou equipamentos de higiene.

Os produtores careciam de treinamento, equipamentos de proteção e estrutura adequada. Assim, muitos sofriam problemas de audição por conta de mergulhos em profundidade. As colônias do molusco eram retiradas do fundo da lagoa com as próprias mãos e braços dos pescadores, o que causava frequentes ferimentos. Havia uma espécie de peixe bagre na região que provocava bastantes lesões nos pescadores, pois ele habitava o fundo da lagoa e, quando o pescador imergia para coletar o sururu, batia com as mãos e braços no peixe, sofrendo cortes que provocavam intensa dor devido a uma a substância liberada pelo animal.

As mulheres mantinham suas crianças próximas durante o beneficiamento, sendo que muitas delas ajudavam no trabalho. Por haver uma avenida às margens da lagoa,era constante o risco de acidentes. Além disso, o bairro era considerado perigoso por conta da criminalidade presente na região. 
Os resíduos da produção eram depositados à beira da avenida para serem coletados pelas organizações de limpeza urbana. Todas as toneladas de resíduos produzidas, cerca de 18,5 por dia, eram levadas para o aterro sanitário como lixo.

A cadeia produtiva também era pouco organizada. Atravessadores costumavam comprar o sururu aos pescadores no próprio local de produção a preços baixos e revendiam a preços altos para o consumidor final. Alguns chegavam a embalar o produto para revender com altíssimo lucro, dando a impressão de ser um produto que passou por um processo industrial.

A pesca do sururu era realizada majoritariamente por homens, cerca de 94,9\% dos trabalhadores que realizam essa atividade, porém, a maior parte das pessoas que trabalhavam com o molusco eram mulheres, aproximadamente $68 \%$. Essas mulheres representavam $93,1 \%$ do total de pessoas que beneficiavam o molusco. Essa etapa tinha a menor remuneração e, ainda assim, consumia a maior parte da mão-de-obra, por volta de $61,2 \%$ do total. Isso explicou a predominância de mulheres na atividade. A média da idade dos produtores era de 34 anos. A renda média bruta mensal individual é de $\mathrm{R} \$ 520,32$ (Coutinho et al., 2014).

Com a finalidade de contornar essa situação, no aspecto econômico, planejou-se o aperfeiçoamento da estrutura de produção do sururu no complexo lagunar Mundaú-Manguaba por meio da profissionalização, mecanização e aplicação de técnicas de produção inovadoras. Esquematizou-se a criação de uma cooperativa formada pelos próprios produtores, que promoveria o beneficiamento do sururu por meio de um processo industrial técnico.

Para isso, contactou-se o O Serviço Nacional de Aprendizagem do Cooperativismo (SESCOOP), entidade integrante do Sistema Cooperativista Nacional, a fim de constituir parceria para treinamento e capacitação dos produtores, bem como obter orientação sobre como criar uma cooperativa.

Como forma de tratar o sururu, identificou-se junto à Secretaria de Estado da Agricultura, Pecuária, Pesca e Aquicultura de Alagoas (SEAGRI) a técnica de depuração, na qual o molusco passa por etapas de lavagem, filtração, cozimento e embalagem que garantem sua total pureza e descontaminação, a fim de ser oferecido com segurança e higiene ao consumidor final. Registraram-se ainda os equipamentos necessários para proteção dos produtores e desenvolvimento da atividade de pesca e beneficiamento.

Quanto à questão social, planejou-se ambiente próprio ao desenvolvimento de ações de apoio às mulheres produtoras em situação de vulnerabilidade social nas instalações da cooperativa. Esse local abrigaria equipamento para o trabalho de dentistas, psicólogos, assistentes sociais e serviço médico para diagnóstico e encaminhamento a postos de saúde ou hospitais da rede pública, fornecidos pelo Poder Executivo Estadual, para atender os produtores, especialmente as mulheres, que representam a maior parte da mão-de-obra. Essa ação teria finalidade de eliminar sua condição de vulnerabilidade social.

Em matéria ambiental, esquematizou-se a guarda e depósito dos resíduos em local adequado, na própria cooperativa, que seria recolhido pelo serviço de limpeza urbana da cidade e encaminhado à organização do terceiro setor, parceira do município, para o aproveitamento dos resíduos, conforme informação da SLUM. 


\section{JUSTIFICATIVA DO PROJETO}

O estado de Alagoas necessitava lidar simultaneamente com a manutenção da extração do sururu como fonte de renda da população local e com a degradação ambiental decorrente. Ocorre que a produção era feita de modo pouco técnica. Não existia um processo de produção adequado para que o sururu fosse produzido e comercializado dentro dos padrões necessários para alcançar seu maior valor comercial.

Isso repercutia nos produtores, carentes de capacitação e equipamentos adequados, especialmente as mulheres, que constituiam a maior parcela da mãode-obra operacional, cerca de $68 \%$. Eram comuns doenças lombares, auditivas, de pele, assim como frequentes lesões decorrentes decorrentes da pesca e beneficiamento do sururu por ausência de equipamentos adequados.

As marisqueiras complementavam seu sustento e de sua família por meio desse trabalho, porém a remuneração é a mais baixa de todo processo produtivo. Esse modelo produtivo, aliado à pobreza e exclusão social dessa população, expunham as produtoras à uma situação de vulnerabilidade.

O projeto de gestão das atividades de produção do sururu em Alagoas objetivou identificar um modelo organizacional ótimo para aprimorar o processo de produção de sururu desenvolvido no Complexo Estuarino Lagunar MundaúManguaba (CELMN). Planejou também ações de apoio às mulheres produtoras em situação de vulnerabilidade, além de propor alternativas para o aproveitamento do potencial econômico de resíduos de processamento do sururu, como a casca.

As principais partes interessadas foram os produtores de sururu da cidade de Maceió, consumidores do sururu (restaurantes, hotéis, supermercados), Universidade Federal de Alagoas - UFAL, Colônias de Pescadores, FEPEAL, SEMUDH, SESCOOP e SLUM.

\section{RELATO DA UTILIZAÇÃO DAS FERRAMENTAS E TÉCNICAS DA GESTÃO DE PROJETOS EM UM PROJETO DE CUNHO SOCIAL}

Nesta seção, relatou-se a utilização de ferramentas e técnicas de gestão de projetos no projeto. Organizou-se conforme as áreas de conhecimento apresentadas pelo PMBOK (PMI 2013), as quais foram apresentadas na revisão bibliográfica deste trabalho.Todas as nove áreas de conhecimento da gestão de projetos foram contempladas na elaboração do projeto.

\section{GESTÃO DO ESCOPO}

A gestão de escopo nos projetos públicos deve atender às finalidades do órgão ou organização patrocinadora. Esses objetivos estão alinhados ao interesse social. No caso do projeto de gestão da produção do sururu, evidenciou-se tal particularidade na presença de ações de sustentabilidade social e ambiental. Tais exigências são oriundas do compromisso com a coletividade e bem-estar social. 
São exigidos inclusive por organizações que fomentam projetos, como é o caso da linha de financiamento do Banco Internacional de Desenvolvimento - BID.

Para garantir que o projeto incluísse todo o trabalho requerido para o seu desenvolvimento, elaborou-se uma estrutura analítica do projeto - EAP, conhecida também como WorkBreakdownStructure - WBS. Conforme Camargo (2014), todo o trabalho do projeto deve estar representado de alguma forma na EAP e, caso não seja, não será trabalho que poderá ser realizado no projeto. A EAP existe basicamente para: Organizar e confirmar o escopo total do projeto;evitar que algum trabalho seja esquecido edetalhar todo o trabalho definido na declaração de escopo.

Desta forma, a EAP foi detalhada conforme Figura 2.

Figura 2 - Estrutura analítica do projeto de gestão da produção de sururu em Alagoas

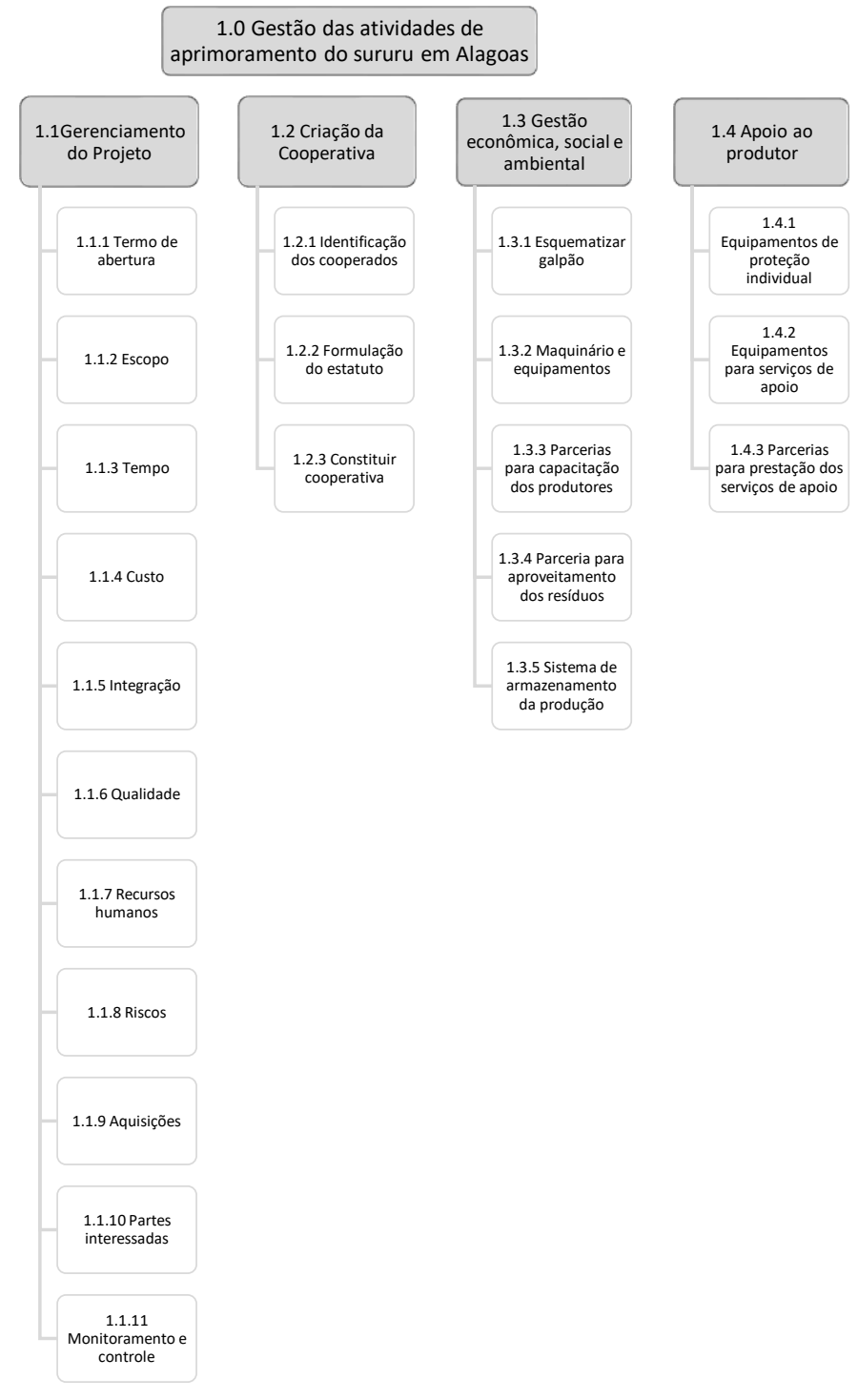




\section{GESTÃO DO TEMPO}

Quanto ao tempo, formulou-se o plano de gerenciamento do tempo, conforme exemplificado por Snyder (2013), estimando a duração de cada atividade listada na EAP. A tabela 1 ilustra a descrição das atividades, horas de trabalho alocadas e tempo estimado de duração.

Tabela1 - Duração das atividades

\begin{tabular}{|c|c|c|c|}
\hline $\begin{array}{l}\text { No } \\
\text { EAP }\end{array}$ & Descrição da atividade & Horas de trabalho & Estimativa de duração \\
\hline 1.1 & $\begin{array}{l}\text { Processo de gerenciamento do projeto: } \\
\text { envolve a confecção dos documentos que } \\
\text { iniciarão o projeto e orientarão sua execução, } \\
\text { quais sejam: termo de abertura, declaração } \\
\text { de escopo, plano de gerenciamento do } \\
\text { projeto, plano de execução, de } \\
\text { monitoramento e de controle. }\end{array}$ & 84 horas úteis & 21 dias \\
\hline 1.2 & $\begin{array}{l}\text { Elaboração do projeto de criação da } \\
\text { cooperativa }\end{array}$ & 198 horas úteis & 49 dias \\
\hline 1.3 & $\begin{array}{l}\text { A execução das atividades de viabilização da } \\
\text { produção e a constituição da estrutura de } \\
\text { apoio ao produtor envolvem a compra dos } \\
\text { materiais e maquinário de produção, a } \\
\text { capacitação dos trabalhadores e a articulação } \\
\text { da rede de comercialização. Abrange } \\
\text { também e a construção do galpão da } \\
\text { cooperativa, que abrigará os espaços } \\
\text { destinados às atividades da produção, área } \\
\text { para depósito de resíduos e os locais } \\
\text { voltados a apoiar os produtores. }\end{array}$ & 2.192 horas úteis & 390 dias \\
\hline 1.4 & $\begin{array}{l}\text { Implementar atividades de amparo social aos } \\
\text { produtores e, em especial, às produtoras em } \\
\text { situação de vulnerabilidade. }\end{array}$ & 240 horas úteis & 90 dias \\
\hline
\end{tabular}

Fonte: Elaborado pelos autores, com base em Snyder (2013)

O setor público demanda processos burocráticos que são restritos às exigências legais que regem a aplicação de recursos públicos. Por conta disso, os projetos públicos demandam um processo de planejamento diferente do setor privado, uma vez que devem prever a demora oriunda do movimento da máquina pública.

Os entraves da burocracia influenciam no tempo de planejamento, aquisição e execução do projeto. Além de serem exigidas diversos procedimentos para contratação do fornecedor, este enfrenta uma série de outros para entrega do bem ou serviço adquirido. Registrou-se, pois, a necessidade de gerir o tempo nos projetos públicos de acordo com os aspectos apresentados. 


\section{GESTÃO DE CUSTOS}

Para se definir os custos, utilizou-se de pesquisa de preços, opinião especializada e estimativas análogas. Os relatórios de status e progresso dos custos do projeto foram elaborados mensalmente. Os custos do projeto foram gerenciados com base no orçamento previsto e pelo fluxo de caixa do projeto.

Foi disponibilizada reserva gerencial no valor de $10 \%$ do orçamento do projeto. A reserva gerencial foi composta pela Reserva de Contingência e Outras Reservas, que, juntamente com o orçamento previsto do projeto, compuseram o custo final do projeto. O limite de controle estabelecido foi de $5 \%$ para mais ou para menos.

As reservas de contingência são reservas destinadas ao gerenciamento de riscos conforme plano de gerenciamento de riscos. As demais reservas são direcionadas a ocorrências de situações não previstas no gerenciamento de riscos.

Em relação aos custos, as aquisições de bens e serviços no setor público devem obedecer aos ditames da Lei 8.666/93, que institui normas para licitações e contratos da Administração Pública. A lei arrola mecanismos mais céleres para aquisição de bens e serviços de menor custo. Dessa forma, é importante aplicar os referidos processos de pesquisa de preços a fim de identificar bens e serviços com melhor custo-benefício, que propiciem maior economia e celeridade ao processo.

Como exemplo, apontou-se a busca por compras enquadradas no inciso II do artigo 24 da citada lei, que permite a dispensa de licitação quando o valor do produto for inferior a $\mathrm{R} \$ \mathbf{8 . 0 0 0 , 0 0}$ na modalidade convite. Assim, ao pesquisar um equipamento de qualidade que possa ser adquirido nessa faixa de preço, também economizar-se-ia tempo, ao evitar um processo de aquisição mais complexo e demorado.

\section{GESTÃO DA INTEGRAÇÃO}

Integração do projeto significa colocar em prática todos os planos das áreas de conhecimento de forma integrada (escopo, tempo, custos etc.) e em conformidade com o plano de gerenciamento do projeto. Todas as áreas e recursos do projeto devem permanecer coesos para produzir os resultados desejados (PMBOK, 2013; SNYDER, 2013).

A integração de todos os componentes previstos no plano de gerenciamento do escopo foi monitorada mediante reuniões semanais, opinião especializada, sistema de informações de gerenciamento de projeto e técnicas de facilitação.

Monitoraram-se os fatores que poderiam impedir o controle integrado de mudanças ou de gerenciamento de configurações para que somente as mudanças aprovadas fossem implementadas.

Aplicou-se com sucesso a gestão da integração do projeto em estudo. Não registraram-se adaptações específicas necessárias a um projeto público em comparação aos projetos privados. 


\section{GESTÃO DE RISCOS}

O gerenciamento de riscos do projeto visa aumentar a probabilidade e o impacto dos eventos positivos e reduzir a probabilidade e o impacto dos eventos negativos no projeto (PMBOK, 2013). Seu planejamento foi feito por meio de técnicas analíticas, opinião especializada e reuniões.

Primeiro, realizou-se a identificação dos riscos por meios de técnicas e ferramentas de revisão da documentação; coleta de informações; análise de premissas; análise de forças, fraquezas, oportunidades e ameaças (SWOT); e opinião especializada.

Depois, empregou-se a análise quantitativa dos riscos por meio de técnicas de coleta e apresentação de dados e opinião especializada. Posteriormente, a análise qualitativa dos riscos foi realizada por meio da avaliação de probabilidade e impacto dos riscos; matriz de probabilidade e impacto; categorização de riscos; avaliação da urgência dos riscos e opinião especializada.

O monitoramento e controle de mudanças dos riscos do projeto foram realizados durante as reuniões de monitoramento e controle do projeto. 0 Gerente de Projetos, auxiliado pela equipe de execução, listou nas pautas das reuniões os riscos com seus respectivos efeitos e as respostas planejadas para cada um. Durante as reuniões, foram avaliadas as modificações dos atributos de situação, probabilidade de ocorrência e valores limites dos riscos, bem como a efetividade dos planos de resposta para cada um.

Para todos os riscos identificados no projeto, o Gerente de Projetos definiu a estratégia de resposta (eliminação, mitigação, aceitação ativa, aceitação passiva ou transferência), segundo os critérios a seguir:

- Eliminação: Alteração de escopo e/ou dos planos do projeto a fim de eliminar a causa do risco, reduzindo a zero a probabilidade de ocorrência deste.

- Transferência: Passar a responsabilidade e impactos do risco para uma terceira parte, geralmente na forma de subcontratação. Um risco transferido não é eliminado, este ainda poderá se materializar, razão pela qual deverá ser monitorado.

- Mitigação: Ações antecipadas para a redução da probabilidade de ocorrência e/ou impacto do risco para tolerâncias baixa, média ou alta. $O$ custo das ações de mitigação do risco deve ser inferior ao impacto deste para o projeto.

- Aceitação: Decisão de não realizar nenhuma ação preventiva (plano de mitigação) em resposta ao risco, em razão da incapacidade da equipe do projeto em tratar o risco.

- Aceitação ativa: Riscos para os quais são planejadas ações de contingência.

- Aceitação passiva: Riscos para os quais não é necessário definir ações de contingência.

Nestes casos, quando o risco ocorria, era avaliada a resposta viável (workaround).

O aporte de recursos para os projetos públicos é, de uma maneira geral, muito mais difícil por conta da burocracia, escassez e eventuais interesses políticos contrários, que restringem seu gerenciamento. Dessa forma, são necessárias técnicas de controle mais restritivas, que suportem níveis menores de riscos, do que aqueles aceitáveis em um projeto privado. 


\section{GESTÃO DE RECURSOS HUMANOS}

O projeto idealizou-se em uma estrutura organizacional tipo funcional. A equipe consultora do projeto contou com três alunos do mestrado profissional em administração pública (PROFIAP / UFAL), um professor orientador e uma gestora de projetos públicos da SEMUDH. A parte executiva ficou por conta da cooperativa, sendo esta dividida nas áreas de produção, resíduos e apoio social, conforme representado na figura 3 .

Figura 3 - Organograma do projeto.
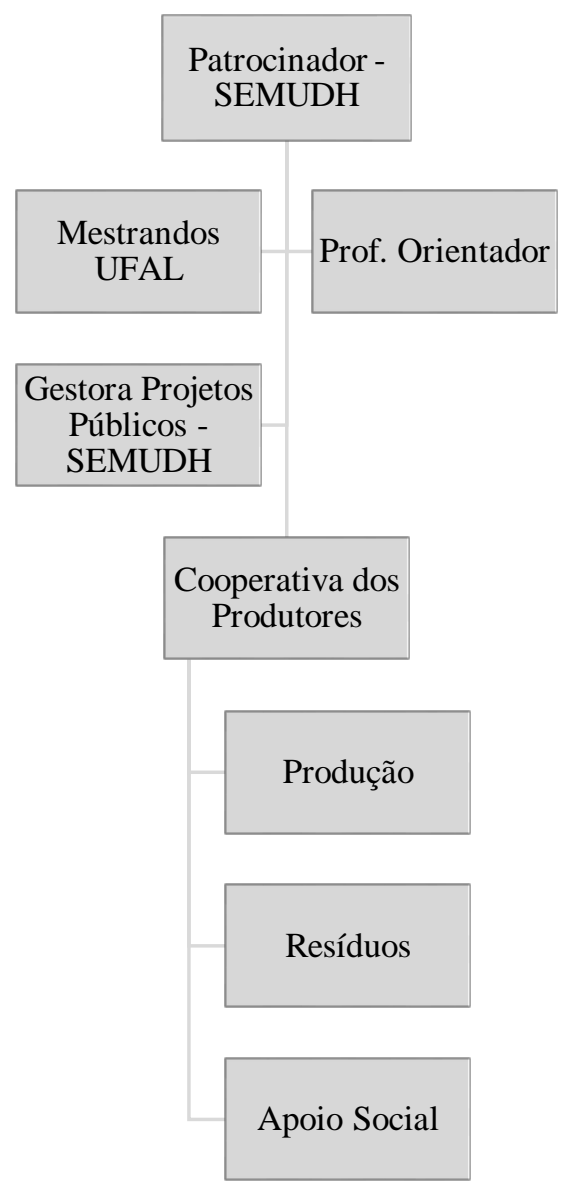

Fonte: Elaborada pelos autores.

Importante destacar que, nos projetos públicos, quando há a necessidade de buscar recursos humanos no mercado, deve-se levar em consideração a legislação pertinente para contratação, ou seja, a aplicação de recursos públicos no projeto leva a uma maior rigidez no processo de contratação, desta forma, o processo de recrutamento e seleção diferencia-se do setor privado.

\section{GESTÃO DA QUALIDADE}

Quanto à qualidade, definiu-se o ciclo PDCA como ferramentas para solucionar suas questões. Essa técnica permitiu um processo constante de controle da qualidade. No projeto em análise, empregou-se com sucesso a referida técnica, sem necessidades de adaptações.

Utilizou-se também o Benchmarking, envolvendo a comparação de práticas 
de outros projetos públicos semelhantes para identificar as melhores práticas, gerar idéias para melhorias e fornecer uma base para medir o desempenho. Projetos similares, que obtiveram êxito, serviram como referência para elaboração do projeto estudado neste artigo.

Dessa forma, com o uso das referidas técnicas de gestão qualidade foi possível assegurar que o projeto mantivesse a qualidade da proposta inicial.

\section{GESTÃO DAS AQUISIÇÕES}

Para as aquisições, planejou-se inicialmente o nível de autoridade de compras, assim, definiu-se que todas as compras deverão passar pela aprovação do gerente do projeto e do patrocinador, bem como eventuais mudanças nos itens a serem adquiridos.

Três documentos foram criados para a concretização de cada aquisição:

- Doc1 - Decisões de Comprar ou Mapa das aquisições.

- As decisões de fazer ou comprar documentam as conclusões obtidas em relação aos produtos, serviços ou resultados do projeto adquiridos fora da organização do projeto ou realizados internamente pela equipe do projeto.

\section{- Doc2 - Pedido de Cotação}

- Usado para fazer cotação dos itens de aquisição quando discussões entre os concorrentes não são necessárias e o preço é o fator principal na negociação

- Doc3 - Termo de recebimento provisório ou definitivo

o Formalização ou Aceita da Entrega do Projeto. Pode ser usada tanto para entregas parciais ou a entrega final do projeto.

Ainda criaram-se critérios de seleção de fonte, tendo pesos diferentes para cada critério selecionado, ou seja, qualidade do produto, preço, prazo de entrega e experiência do fornecedor.

Como demonstrado na gestão dos custos, o critério preço teve peso maior na decisão da compra, haja vista as particularidades das compras públicas.

\section{GESTÃO DAS COMUNICAÇÕES}

De forma a assegurar que as informações geradas, durante a realização do projeto, (documentos, procedimentos, relatórios, atas de reuniões, dentre outros) fossem coletadas, armazenadas e recuperadas de maneira adequada, utilizou-se um gerenciador de conteúdo. Esta ferramenta consiste em um web site (dropbox.com), que pode ser configurado para ter seu conteúdo compartilhado entre um determinado grupo. Dessa forma, foi possível gerenciar a divulgação das informações, bem como as alterações na documentação, que só podem ser feitas pelos autores do projeto.

A divulgação do andamento do projeto e suas constantes atualizações foram realizadas por meio de reuniões, e-mails e telefonemas com a secretaria de estado da mulher e direitos humanos e demais parceiros do projeto, como a Universidade Federal de Alagoas. Os autores do projeto ficaram responsáveis pela apresentação e divulgação do projeto aos patrocinadores em evento realizado na Secretaria de Planejamento e Gestão do Estado de Alagoas - SEPLAG. 
Identificou-se que, nos projetos públicos, diante da escassez de recursos ou da burocracia necessária para sua utilização, o uso de meios de comunicação gratuitos, como as redes sociais e os sistemas online de compartilhamento de arquivos, são excelentes alternativas para a gestão das comunicações.

\section{CONSIDERAÇÕES FINAIS}

O objetivo deste trabalho foi validar a aplicabilidade de ferramentas e técnicas de gestão de projetos em projetos públicos, especialmente aquelas elencadas no PMBOK, que normalmente são utilizadas em projetos privados.

Identificou-se que a forma como operam as organizações públicas difere significativamente das organizações privadas, principalmente por causa das legislações específicas e do público alvo a ser atingido ou beneficiado, que, no caso das organizações privadas, é o cliente e, no caso das organizações públicas, é a sociedade como um todo.

Esclareceu-se que a legislação e o interesse público interferem significativamente no gerenciamento de projetos públicos. Quase todas as áreas de conhecimentos são afetadas, conforme discutido, a fim de atenderem às particularidades do setor público. Porém, registrou-se que são viáveis adaptações para promover o gerenciamento de projeto público por meio das técnicas de gestão de projetos dos manuais e guias aplicados.

A utilização de ferramentas e técnicas de gestão de projetos foi essencial ao sucesso do projeto. Por intermédio delas, foi possível determinar com clareza os objetivos perseguidos e as etapas a serem concluídas. O plano de gerenciamento empregado resultou em diversos benefícios ao projeto, como economia de tempo e recursos financeiros por meio de técnicas de pesquisa de preços e programação de atividades, previsão de horas de trabalho, de tempo de duração das etapas.

Além disso, proporcionou emprego de técnicas de controle de qualidade, confiabilidade da comunicação, distribuição adequada das atividades entre as equipes, mapeamento de todas as atividades necessárias para desenvolver o projeto e monitoramento dos prazos estabelecidos para o desenvolvimento dessas atividades, assegurando melhor controle, dentre outros.

Dessa forma, validou-se a hipótese levantada neste artigo, pois o emprego de ferramentas e técnicas de gestão de projetos nos projetos públicos proporcionou a racionalidade das atividades burocráticas e gerou, como consequência, maior celeridade na execução do projeto desenvolvido, com maior transparência, economia e menores riscos de insucesso.

Assim, diante do ganho que estas ferramentas e técnicas podem proporcionar ao serviço público, seja ele em qual esfera for, sugerem-se como trabalhos futuros, o desenvolvimento de pesquisas voltadas à sua utilização em projetos públicos e aprimoramento de seus resultados. 


\title{
Management of Sururu production activities in Alagoas: report of the utilization of project management tools and techniques
}

\begin{abstract}
This article validated the application of project management tools and techniques in public projects through a practical case directed to the management of sururu's production activities in an environmentally and socially sustainable way in the State of Alagoas. It were examined the particularities of public projects, how they interfere with the management process and what tools and techniques are most appropriate to be applied in this process. Finally, it was evaluated the project formulated to improve the production of sururu constituted with the application of the tools and techniques of the Project Management Body of Knowledge (PMBOK) and its extension for the public sector, the Government Extension to A Guide to the Project Management Body of Knowledge. The results analysis showed the main aspects of a public project management process focused on a productive sector, aligned with environmental and social responsibility actions and based on the instructions of the PMBOK guide, as well as recorded the particularities of the public sector to be observed in each stage. It was concluded that the PMBOK tools and techniques met the demands of the studied public project management process, facilitated its management and adapted to its peculiarities.
\end{abstract}

KEY WORDS:projects administration;economic development projects,social development projects; project management body of knowledge (PMBOK). 


\section{REFERENCIAS}

CAMARGO, Marta. Gerenciamento de projetos: fundamentos e prática integrada. Elsevier Brasil, 2014.

CARVALHO, MM de; RABECHINI JR, Roque. Fundamentos em gestão de projetos: construindo competências para gerenciar projetos. São Paulo: Atlas, 2011.

COUTINHO, Mauro Knupferet al. A Cada Lata: A Extração do Sururu na Lagoa Mundaú - Alagoas.Cooperação Brasil-Espanha para o desenvolvimento de Alagoas. Brasíla: labs, 2014.

CAVALIERI, Adriane. Como se tornar um profissional em gerenciamento de projetos. Rio de Janeiro: Qualitymark, 2008.

GIL, Antônio C. Como elaborar projetos de pesquisa. 5. ed. São Paulo: Atlas, 2010.

GOOGLE. Google acadêmico.2016. Disponível em:

<https://scholar.google.com.br/>. Acesso em: 10 jan. 2017.

LEITE, Ramon Silva. O Desafio de Implementar a Estratégia: uma análise da utilização do Gerenciamento de Projetos com Ferramenta de Implantação da Estratégia do Governo de Minas Gerais.In: XXXIII Encontro da ANPAD. 2009, São Paulo. Anais... . Disponível em:

$<$ https://www.researchgate.net/profile/Ramon Leite/publication/304581571 O Desafio de Implementar a Estrategia uma analise da utilizacao do Gerenci amento de Projetos com Ferramenta de Implantacao da Estrategia do Gov erno de Minas Gerais/links/5774389c08aead7ba06e61a8.pdf>. Acesso em: 9jan. 2017.

HELDMAN, Kim. Gerência de projetos: PMP Project Management Professional: guia para o exame oficial do PMI. ELSEVIER, 2006.

MACCARI, Emerson Antonio; DOS SANTOS TEIXEIRA, Gislaine Cristina. Estratégia e planejamento de projeto para acompanhamento de alunos egressos de programas de pós-graduação stricto sensu. Revista de Administração da UFSM, v. 7, n. 1, p. 101-116, 2014.

MARCONI, Marina de Andrade; LAKATOS, Eva Maria. Fundamentos de metodologia científica. In: Fundamentos de metodologia científica. Atlas, 2010. 
MAXIMIANO, Antônio Amaru. Administração de Projetos: Como transformar ideias em projetos. São Paulo: Editora Atlas, 2002.

MUNNS, A. K.; BJEIRMI, Bassam F.The role of project management in achieving project success. International journal of project management, v. 14, n. 2, p. 8187, 1996.

PMBOK, GUIDE. Um guia do conhecimento em gerenciamento de projetos. 2013.

PROJECT MANAGEMENT INSTITUTE (PMI). Government Extension to A Guide to the Project Management Body of Knowledge. Exposure Draft $\subset 2001$ Project Management Institute.

RABECHINI JR, Roque; CARVALHO, Marly Monteiro de; LAURINDO, Fernando José Barbin. Fatores críticos para implementação de gerenciamento por projetos: 0 caso de uma organização de pesquisa. Revista Produção, v. 12, n. 2, p. 28-41, 2002.

SCIENTIFIC ELECTRONIC LIBRARY ONLINE - SCIELO. Biblioteca científica eletrônica online .Disponível em: <http://http://www.scielo.org/>. Acesso em: 9 jan. 2017.

SCIENTIFIC PERIODICALS ELECTRONIC LIBRARY - SPELL.Sistema de busca de artigos. Disponível em: <http://www.spell.org.br/>. Acesso em: 7 jan. 2016.

SHENHAR, Aaron J. Reinventando gerenciamento de projetos: a abordagem diamante ao crescimento e inovação bem-sucedidos. 2010.

SILVA, Edson Coutinho da; GIL, Antonio Carlos. Inovacao e gestao de projetos: os" fins" justificam os" meios". Revista de Gestão e Projetos, v. 4, n. 1, p. 138, 2013.

STACKPOLE, Cynthia Snyder. A Project Manager's Book of Forms: A Companion to the PMBOK Guide. John Wiley\& Sons, 2013.

SOUZA, Enock Godoy de; REINHARD, Nicolau. Uma Revisão Bibliográfica Dos Fatores Ambientais Que Influenciam A Gestão De Projetos De Sistemas De Informação No Setor Público. Revista de Gestão e Projetos-GeP, v. 6, n. 2, p. 2741, 2016.

TUMAN, G.J. Development and Implementation of Effective Project Management Information and Control Systems, In: CLELAND, D. I.; KING, W, R. Project 
VALERIANO, Dalton L. Gerência em projetos: pesquisa, desenvolvimento e engenharia. Pearson Education, 2004.

VITORELI, Gislaine Aparecida et al. Relato da utilização de ferramentas e técnicas de gestão de projetos em um projeto de pesquisa acadêmica. Gepros: Gestão da Produção, Operações e Sistemas, v. 5, n. 4, p. 111, 2010.

WIRICK, David. Public-sector project management: Meeting the challenges and achieving results. John Wiley\& Sons, 2011.

Recebido: 18 mar. 2017

Aprovado: 10 jun. 2017

DOI: $10.3895 /$ rbpd.v6n3.5330

Como citar: COSTA, C. E. S.; PIERRE, V. H. L.; ALMEIDA, D. C.; COSTA, A. C. S.; SOUZA, W. A. R.

Gestão das atividades de produção do Sururu em Alagoas: relato da utilização de ferramentas e técnicas de gestão de projetos. R. bras. Planej. Desenv.,Curitiba, v. 6, n. 3, p. 484-505, set./dez. 2017. Disponível em: $<$ https://periodicos.utfpr.edu.br/rbpd>. Acesso em: XXX.

Correspondência:

Carlos Eugênio Silva Da Costa

Av. Lourival Melo Mota - Tabuleiro do Martins, Rio Largo, Alagoas, Brasil

Direito autoral: Este artigo está licenciado sob os termos da Licença CreativeCommons-Atribuição 4.0

Internacional.

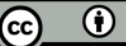

